\section{Conditions for Permeabi- lization of Cells Used for Intracellular Tyrosine Phosphorylation Studies}

BioTechniques 27:435-437 (September 1999)

Permeabilized cells are widely applied for studying the effect of membrane impermeant biomolecules on signaling pathways. After permeabilization with reagents commonly used for this purpose, the architecture of the cells remains essentially intact, and hence, they retain their ability to respond to cell surface receptor stimulation as far as early cellular responses are concerned. Early signaling events, such as tyrosine and serine phosphorylation of cellular proteins $(3,6)$, generation of cAMP (1) or inositol-phosphate hydrolysis (3) can be investigated after the stimulation of permeabilized cells.

Several procedures have been reported to produce permeable cells. These methods apply bacterial toxins such as tetanolysin $(1,2,9)$ and streptolysin-O (SLO) $(2,3)$ or detergents like digitonin (5) and L- $\alpha$-lysophosphatidyl choline (LPC) $(6,8)$ as permeabilizing agents. However, a common feature of most of the permeabilizing reagents is that they induce a significant tyrosine

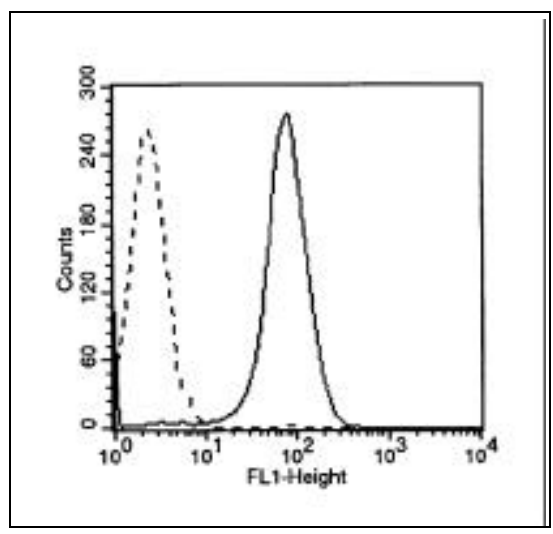

Figure 1. Intracellular staining of permeabilized cells. Intact (dotted line) or LPC-permeabilized J6 cells (continuous line) were stained with a rabbit antibody against a recombinant protein representing the intracellular domain of the CD43 (produced in our laboratory) and subsequent incubation of cells with FITC-labeled, antirabbit immunoglobulin (Sigma, St. Louis, MO, USA). The immunofluorescence was analyzed by cytofluorimetry on a FACSVantage ${ }^{\mathrm{TM}}$ Instrument (Becton Dickinson, San Jose, CA, USA). phosphorylation in most of the leukemic cell lines, which might obscure the regulatory effect of the biomolecules that are tested (References 6 and 9, and unpublished observation).

Our aim was to establish a permeabilization procedure that resolves this problem. Therefore, we first compared different reagents, namely SLO, digitonin and LPC and various conditions for permeabilization to select the most efficient system. SLO-mediated permeabilization required a high concentration of SLO (200 IU/mL) and a long time (30 $\mathrm{min})$ to fully permeabilize $10^{7}$ J6 cells or peripheral blood mononuclear cells (PBMC) at $37^{\circ} \mathrm{C}$ (data not shown). Permeabilization with digitonin also required $10-30 \mathrm{~min}$, and it was not well reproducible. The LPCmediated permeabilization has turned out to be the most reliable, because it was highly reproducible in the case of different cells (leukemic cell lines, peripheral mononuclear cells), and the permeabilization was completed in a short time. Therefore, the LPC-mediated permeabilization (6) was characterized and optimized for studying the effect of various biomolecules on tyrosine phosphorylation. The amount of LPC, the appropriate time and the optimal temperature required for permeabilization have been established in a series of experiments. The LPC of 50 $\mu \mathrm{g} / \mathrm{mL}$ permeabilized a wide variety of cell lines at $10^{7}-10^{8}$ cell $/ \mathrm{mL}$ concentration within $1 \mathrm{~min}$ (data not shown). Permeabilization carried out at $4^{\circ}$ or $37^{\circ} \mathrm{C}$ was equally efficient (data not shown). Permeability of the cells was assessed in each experiment using trypan blue exclusion. The efficiency of the LPC permeabilization was also assessed by introducing fluorescein isothiocyanate (FITC)-labeled peptides of 2 and $4 \mathrm{kDa}$ molecular mass (data not shown) and FITC-labeled immunoglobulin $(150 \mathrm{kDa})$ into the cells (Figure 1). An antibody recognizing the intracellular domain of the CD43 molecule stained over $95 \%$ of the permeabilized cells confirming the successful permeabilization (Figure 1).

The method we finally preferred for permeabilization was as follows: the human leukemic T cells (J6) were centrifuged, washed once with the cell culture medium RPMI (Life Technologies, 
Gaithersburg, MD, USA), resuspended at $4 \times 10^{7}$ cells $/ \mathrm{mL}$ in ice-cold permeabilization buffer (6) $\left[10 \mathrm{mM} \mathrm{MnCl}{ }_{2}\right.$, $10 \mathrm{mM} \mathrm{Mg}(\mathrm{OAc})_{2}, 296 \mu \mathrm{M} \mathrm{CaCl}_{2}, 2$ mM EGTA, 40 mM HEPES, $\mathrm{pH}$ 7.4] and incubated further on ice for $5 \mathrm{~min}$ in a cold room. Permeabilization was initiated by adding $1 / 10$ volume of icecold LPC stock solution containing 500 $\mu \mathrm{g} / \mathrm{mL}$ LPC.

We determined whether permeabilized $\mathrm{T}$ cells were able to respond to $\mathrm{T}$ cell receptor (TCR) stimulation with an anti-CD3 antibody (UCHT-1) by analyzing the TCR-induced tyrosine phosphorylation and whether this response was comparable to that of intact cells. As Figure 2 shows, a low level of tyrosine phosphorylation was detected in unstimulated cells, either intact or LPC permeabilized (Figure 2, A and B, lanes 1). Moreover, permeabilization did not affect the TCR-induced tyrosine phosphorylation (Figure 2B, lane 2) because it was similar to that of unpermeabilized cells (Figure 2A, lane 2). Similar tyrosine phosphorylation was induced when the stimulant was added 15 min after permeabilization. After 30 min passing permeabilization, the cell response declined, but still a considerable tyrosine phosphorylation was detected upon stimulation (data not shown). Phosphorylation of intracellular substrates was also detected in the presence of $[\gamma-32 \mathrm{P}]$ ATP by determining the incorporation of ${ }^{32} \mathrm{P}$ into the proteins upon stimulation of permeabilized cells by the TCR (data not shown). The temperature conditions during permeabilization dramatically influenced the overall tyrosine phosphorylation. In cells permeabilized at $37^{\circ} \mathrm{C}$, a high background signal was induced that concealed the effect of TCR stimulation (Figure 2C). When the low temperature was not strictly controlled during the permeabilization, namely the procedure was not done in a cold room, keeping the samples and reagents on ice, the LPC-induced tyrosine phosphorylation in unstimulated cells was always observed (data not shown). We examined whether the composition of

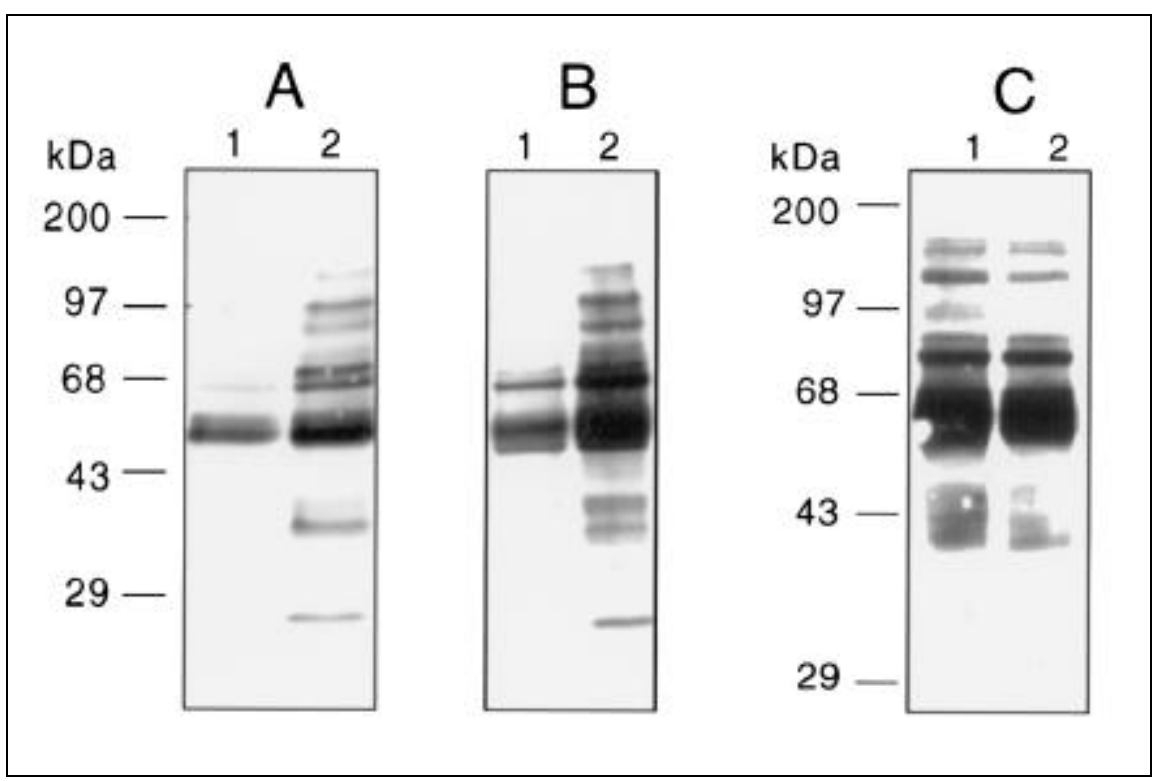

Figure 2. Tyrosine phosphorylation induced by TCR in intact and permeabilized cells. Intact J6 cells (A) or J6 cells permeabilized with LPC (Sigma) on ice (B) or at $37^{\circ} \mathrm{C}(\mathrm{C})$ were stimulated with 10 $\mu \mathrm{g} / \mathrm{mL}$ UCHT- 1 for $2 \mathrm{~min}$ at $37^{\circ} \mathrm{C}$ (lanes 2) or were left unstimulated (lanes 1). The activation was stopped by adding $2 \times$ ice-cold lysis buffer [50 mM HEPES, $\mathrm{pH} 7.4,1 \%$ Triton ${ }^{\circledR} \mathrm{X}-100,150 \mathrm{mM} \mathrm{NaCl}$, $20 \mathrm{mM} \mathrm{NaF}, 2 \mathrm{mM}$ sodium orthovanadate, $2 \mathrm{mM}$ EDTA, $10 \mathrm{mM}$ sodium pyrophosphate, $1 \mathrm{mM}$ phenylmethylsulfonylfluoride (PMSF), $10 \mu \mathrm{g} / \mathrm{mL}$ aprotinin and leupeptin]. Postnuclear supernatants were mixed with $2 \times$ sodium dodecyl sulfate (SDS) Laemmli buffer (7), boiled for 5 min and loaded onto a $10 \%$ SDS polyacrylamide gel. After electrophoresis, proteins were transferred onto nitrocellulose membrane and hybridized with anti-phospho-tyrosine mAb, 4G10 (Upstate Biotechnology, Lake Placid, NY, USA), then peroxidase-labeled, anti-mouse Ig (DAKO, Carpinteria, CA, USA). Finally, the hybridizing protein bands were visualized with enhanced chemiluminescence (ECL) detection system (reagents for ECL were purchased from Sigma). permeabilizing buffer used during stimulation affected the phosphate incorporation into cellular substrates or the phosphorylation background of the unstimulated control. Addition of exogenous ATP to the buffer did not improve the efficiency of the phosphate incorporation. The effect of bivalent cations, $\mathrm{Ca}^{2+}, \mathrm{Mg}^{2+}$ and/or $\mathrm{Mn}^{2+}$, in the permeabilizing buffer to the LPC-induced background phosphorylation at a higher temperature, was also tested. The presence or absence of one or the other ion in the buffer did not affect the background. However, omitting $\mathrm{Mg}^{2+}$ and $\mathrm{Mn}^{2+}$ simultaneously from the buffer resulted in the dramatic decrease in the inducibility of the tyrosine phosphorylation (data not shown). This result likely reflects the requirement of at least one of these ions for optimal function of the tyrosine kinases.

Next, we analyzed whether the cells, permeabilized in the above-described

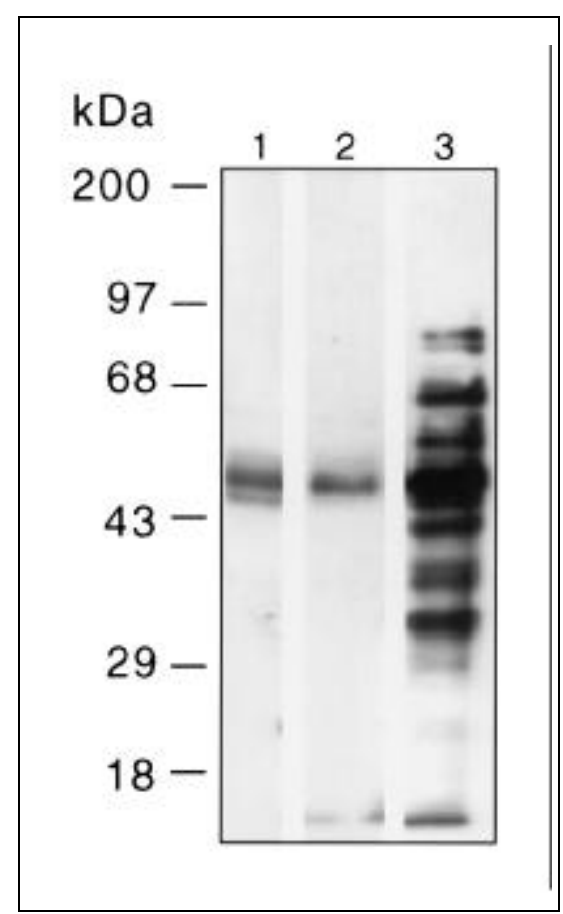

Figure 3. Stimulation of tyrosine phosphorylation by TCR $\zeta$ peptides in LPC-permeabilized J6 cells. Cells, permeabilized with LPC were untreated (lane 1) or were treated with synthetic oligopeptide derived from the TCR $\zeta$ chain in unphosphorylated (lane 2) or tyrosine-phosphorylated (lane 3) forms. The amino acid sequence of the peptide in single letter code was NQLY*NELNLGRREEY*DVL, where Y* represented tyrosine residues in unphosphorylated or phosphorylated form (4). 
manner, were suitable for studying the intracellular tyrosine phosphorylation induced by a membrane impermeable synthetic peptide. A synthetic phosphopeptide (sequence is presented in legend for Figure 3) derived from the TCR $\zeta$ subunit (4) and its nonphosphorylated counterpart were introduced into LPCpermeabilized J6 cells. This sequence represented a conserved signal transducing motif, called immunoreceptor tyrosine-based activation motif (ITAM) that was previously shown as an effective modulator of the cell response in permeabilized cells $(6,9)$. As Figure 3 shows, the phospho-peptide induced a high level of phosphorylation compared to that of unstimulated cells or cells stimulated with non-phosphorylated peptide.

The procedure described here allows a fast and efficient permeabilization of a variety of leukemic cell lines without affecting the responsiveness of the cells to external stimuli. Additionally, a wide variety of biomolecules, including antibodies against intracellular antigens, can be introduced into leukemic cells permeabilized in this manner. Due to the simplicity and high efficiency of this procedure, we recommend its use to determine the effect of membrane impermeant biomolecules on tyrosine phosphorylation pathways in leukemic cells. We would like to emphasize the importance of the well-controlled, low temperature during permeabilization, which is a key factor for successful usage of permeabilized cells for signal transduction studies.

\section{REFERENCES}

1.Alava, M.A., K.E. DeBell, A. Conti, T. Hoffmann and E. Bonvini. 1992. Increased intracellular cyclic AMP inhibits inositol phospholipid hydrolysis induced by perturbation of the $\mathrm{T}$ cell receptor/CD3 complex but not by Gprotein stimulation. Biochem. J. 284:189-199.

2.Bonvini, E., K.E. Debell, M.S. Taplits, C.

Brando, A. Aurenza, K. Seamon and T. Hoffman. 1991. A role for guanine-nucleotide-binding proteins in mediating T-cellreceptor coupling to inositol phospholipid hydrolysis in a murine T-helper (type II) lymphocyte clone. Biochem. J. 275:689-696.

3.Graves, J.D., S.C. Lucas, D.R. Alexander and D.R. Cantrell. 1990. Guanine nucleotide regulation of inositol phospholipid hydrolysis and CD3-antigen phosphorylation in permeabilized T lymphocytes. Biochem. J. 265:407413.
4.Hegedüs, Z., V. Chitu, G.K. Tóth, Cs. Finta, Gy. Váradi, I. Andó and É. Monostori. 1999. Contribution of kinases and the CD45 phosphatase to the generation of tyrosine phosphorylation patterns in the TCR $\zeta$ chain. Immunol. Lett. 67:31-39.

5.Jekunen, A.P., D.R. Shalinsky, D.K. Hom, K.D. Albright, D. Heath and S.B. Howell. 1993. Modulation of cisplatin cytotoxicity by permeabilization of the plasma membrane by digitonin in vitro. Biochem. Pharmacol. 45:2079-2085.

6.Johnson, S.A., C.M. Pleiman, L. Pao, J. Schneringer, K. Hippen and J.C. Cambier. 1995. Phosphorylated immunoreceptor signalling motifs (ITAMs) exhibit unique abilities to bind and activate lyn and syk tyrosine kinases. J. Immunol. 155:4596-4603.

7.Laemmli, U.K. 1970. Cleavage of structural proteins during the assembly of the head of bacteriophage T4. Nature 227:680-685.

8.Nomura, S., T. Kamya and M. Oishi. 1986. A procedure to introduce molecules into living mammalian cells. Exp. Cell Res. 163:434444.

9.Wange, R.L., N. Isakov, T.R. Burke, Jr., A. Otaka, P.P. Roller, J.D. Watts, R. Aebersold and L.E. Samelson. 1995. $\mathrm{F}_{2}(\mathrm{Pmp})_{2}-$ $\mathrm{TAM} \zeta_{3}$, a novel competitive inhibitor of the binding of ZAP-70 to the T cell antigen receptor, blocks early $\mathrm{T}$ cell signaling. J. Biol. Chem. 270:944-948.

This work was supported by OTKA T026637, T16156, T29706 and ETT 672. We thank Kinga Székely Szücs for the excellent technical assistance, Mrs. Mária Tóth and András Borka for preparing the photoprints. We are grateful to the Bástyai-Holczer Foundation for contributing to the cost of the publication of this paper. We thank Prof. P.C.L. Beverley for the UCHT1 antibody. Address correspondence to Dr. Éva Monostori, Institute of Genetics, Biological Research Center of Hungarian Academy of Sciences, H-6701 Szeged, P.O. Box 521, Hungary. Internet: monos@nucleus.szbk. u-szeged.hu

Received 28 December 1998; accepted 3 June 1999.

\section{Violeta Chitu, Dmytro Demydenko, Gábor K. Tóth', Zoltán Hegedüs and Éva Monostori Biological Research Center of the Hungarian Academy of Sciences \\ ${ }^{1}$ A. Szentgyörgyi Medical University Szeged, Hungary}

